\title{
O positivismo como fundamento epistemológico clássico das políticas educacionais e a institucionalização da prática escolar na contemporaneidade
}

\section{Positivism as classical epistemological framework of educational policy and school practice institutionalization in contemporaneity}

\section{El positivismo como fundamento epistemológico clásico de las políticas educativas y la actividad escolar en la actualidad}

\author{
Lindomar Wessler Boneti*
}

\begin{abstract}
Resumo: Este artigo constitui-se de uma reflexão epistemológica em políticas educacionais na perspectiva de contribuir com o debate da Red Latinoamerica de Estudios Epistemológicos en Política Educativa (ReLePe). Trata-se de resgatar o caminhar histórico da posição Positivista como fundamento epistemológico clássico da institucionalização das políticas educacionais no que se refere à implementação da ação educativa, com foco especial ao conjunto de regras, de normas e de valores que regem o fazer da escola. Argumenta-se que esses fundamentos constituem-se a partir de dois movimentos interligados: construção histórica dos fundamentos epistemológicos da ciência e do Estado Moderno que, com o novo modo de produção, o capitalismo, dá origem ao segundo: movimento burguês de distinção de classe com base no estilo de vida. Assim, a partir da "Razão Moderna", delineou-se o que se pode considerar como um "modelo de civilidade", passando a se constituir o fundamento epistemológico e a meta de realização da institucionalização das políticas educacionais e a atividade escolar na contemporaneidade.
\end{abstract}

Palavras-chave: Políticas Educacionais. Fundamentos epistemológicos. Positivismo.

Abstract: This article consists of an epistemological reflection on educational policies
in order to contribute to the Red Latinoamerica de Estudios Epistemológicos en
Política Educativa (ReLePe) debate. It is about to rescue the historical journey of the
positivist position as classical epistemological framework of the educational policy

* Professor da Pontifícia Universidade Católica do Paraná (PUCPR). E-mail: <lindomar@boneti.com> 
institutionalization with regard to the implementation of educational action, with special focus to the set of rules, norms and values that conduct school activity. It is argued that these frameworks are constituted from two interconnected movements: historical construction of the epistemological frameworks of science and the Modern State that with the new mode of production, capitalism, gives rise to the second one: bourgeois movement of class distinction based on lifestyle. Thus, from the "Modern Reason", it was outlined what may be regarded as a "model of civility", becoming the epistemological framework and goal of achieving the educational policy institutionalization and school activity in contemporaneity.

Keywords: Educational Policy. Epistemological frameworks. Positivism.

Resumen: Este texto se constituye como una reflexión epistemológica en políticas educacionales, con la perspectiva de contribuir al debate que se realiza en el ámbito de la ReLePe - Red Latinoamericana de Estudios Epistemológicos en Política Educativa-. Aquí se trata de rescatar el caminar histórico de la aparición de la posición positivista como fundamento como fundamento epistemológico clásico de la institucionalización de las políticas educacionales en lo que se refiere a la implementación de la acción educativa, con foco especial al conjunto de reglas, normas y valores que rigen el hacer de la escuela. Se argumenta que los fundamentos epistemológicos positivistas de las políticas educacionales las cuales se expresan en la institucionalización de la práctica escolar y su conjunto de normas y reglas se constituyen como parte de una construcción histórica de los fundamentos epistemológicos de la ciencia y del Estado Moderno, el cual, con la llegada de nuevo modo de producción, el capitalismo, da origen al segundo, el movimiento burgués de distinción de clases que se basa en su estilo de vida. Estos dos movimientos juntos, a partir del precepto de la "Razón Moderna", delinearon lo que se puede considerar como un "modelo de civilidad" pasando, este, a constituirse en fundamento epistemológico y meta de realización de la institucionalización de las políticas educacionales y la actividad escolar en la actualidad.

Palabras clave: Políticas Educativas. Fundamentos epistemológicos. Positivismo.

\section{Introdução}

Este artigo constitui-se de uma reflexão epistemológica em políticas educacionais na perspectiva de contribuir com o debate que se realiza especialmente no âmbito da Red Latinoamerica de Estudios Epistemológicos en Política Educativa (ReLePe). Nesse debate tem se dado especial atenção à "posição" epistemológica no estudo das políticas educacionais considerando "[...] a categoria 'Epistemologias' no plural dado que existem diversos posicionamentos e perspectivas epistemológicas para desenvolver e levar a cabo uma investigação 
em política educativa [...]" (ALMEIDA; TELLO, 2013, p. 13). Portanto, nesse debate, toma-se como ponto de partida e dá-se importância ao pressuposto da inexistência da neutralidade quando se trata de pesquisa e, por conseguinte, da produção do conhecimento, o que leva necessariamente a uma tomada de "posição" epistemológica na atividade da investigação em política educacional, como bem salienta (TELLO, 2013).

Com o foco na posição epistemológica na produção do conhecimento no campo das políticas educacionais, há contribuições significativas oriundas desse debate que ocorre no âmbito da ReLePe, a saber: Masson e Mainardes (2013), Kaplan e Napoli (2013), Almeida e Silva (2013). E, também, outros enfoques teóricos e metodológicos no estudo de políticas educacionais, tais quais: Mainardes e Gandin (2013), Ruiz (2013), Gorostiaga (2013), Blasco (2013), Gorostiaga e Tello (2013).

No entanto, Tello (2013), ao abordar o campo do estudo das políticas educacionais, dos fundamentos epistemológicos da sua institucionalização, como o "[...] conjunto de práticas, sentidos, mecanismos regulatórios [...]" (TELLO, 2013, p. 33), no processo da investigação de políticas educacionais, sugere uma nova temática de debate, a da institucionalização, não apenas no âmbito da produção do conhecimento, como dedica a análise feita pelo autor citado, mas algo ainda diferente: nos fundamentos epistemológicos da prática escolar na contemporaneidade. Ou seja, o pesquisador sugere o resgate do caminhar histórico do advento da posição Positivista como fundamento epistemológico clássico da institucionalização das políticas educacionais no que se refere à implementação destas, expressas no conjunto de regras, normas e valores que regem o fazer da escola.

A partir das precisões conceituais de epistemologia das políticas educacionais feitas por Saviani (2013), seria de buscar evidenciar o Positivismo como a "teoria" do conhecimento a partir da qual se institui o conjunto de normas, de regras e de valores que regem o fazer da escola e a repercussão dessa prática no contexto social contemporâneo.

Como forma de aprofundar esse debate, neste texto, além de se resgatar o processo da construção histórica dos fundamentos epistemológicos da instituição escolar, com base na posição Positivista, faz-se um ensaio de evidenciar tais fundamentos na prática do dia a dia da escola na contemporaneidade e suas repercussões, especialmente no que diz respeito à receptividade das diferenças sociais no espaço escolar. $\mathrm{O}$ argumento central deste texto expressa-se, assim, a partir de seis aspectos interligados a serem considerados:

1. A "Filosofia Positiva" de Augusto Comte (1991), sistematizada no Século XIX, constitui-se de um somatório de elementos epistemológicos construídos 
historicamente, especialmente a partir da construção dos fundamentos teóricos da Ciência Moderna e do Estado Moderno. Assim sendo, o Positivismo, no âmbito da Modernidade, passa a se constituir não apenas de um Método de compreensão do real, mas de intervenção sobre ele, constituindo-se, assim, em fundamentos epistemológicos do Estado Moderno e, portanto, das políticas educacionais na modernidade.

2. Os fundamentos epistemológicos positivistas constituem fundamentos epistemológicos das políticas educacionais e, portanto, se expressam na prática do dia a dia da escola na contemporaneidade, por meio da sua institucionalização e do seu conjunto de normas, de regras e de valores.

3. Os fundamentos epistemológicos positivistas das políticas educacionais constituem-se de uma construção histórica a partir de dois movimentos interligados: o primeiro diz respeito à construção histórica dos fundamentos epistemológicos da ciência e do Estado Moderno que, com o advento do novo modo de produção, o capitalismo, dá origem ao segundo, o movimento burguês de distinção de classe com base no estilo de vida.

4. Estes dois movimentos, o da construção histórica dos fundamentos clássicos da Ciência e do Estado moderno, o Positivismo, e o movimento burguês de distinção de classe, juntos, com o advento da modernidade, delinearam o que se pode considerar como um "modelo de civilidade", passando este, a partir de então, a se constituir meta de realização da atividade escolar, ou seja, o seu conjunto de normas, de regras e de valores.

5. Esse arcabouço institucional da escola, representado pelo seu conjunto de normas, de regras e de valores, tendo como base o positivismo clássico, mantém-se imutável durante todo o período histórico das políticas educacionais brasileiras, mesmo que diferentes eventos (políticos, econômicos, culturais, etc.) nos diferentes momentos históricos, contribuíram com a busca de alterações significativas dos fins e das significações conceituais da educação, como é o caso da receptividade às diferenças e às desigualdades sociais no espaço escolar.

6. A funcionalidade técnica, expressa especialmente pelo pressuposto da homogeneidade e da evolução, ingredientes positivistas típicos, presentes na composição do arcabouço institucional e, portanto, no conjunto de normas, de regras e de valores da escola, impõe obstáculo à receptividade, pela escola, das diferenças e das desigualdades sociais na contemporaneidade.

O que se propõe com este texto é identificar os principais ingredientes construídos no contexto da construção histórica do pensamento Positivo no âmbito desses dois movimentos salientados acima e como eles se apresentam no arcabouço institucional da escola como um conjunto de normas, de regras e de valores. Esse desafio de análise pode levar a se compreender as possibilidades 
e os limites de a escola romper com a hegemonia da homogeneidade burguesa na perspectiva de receber as diferenças sociais no espaço escolar. Metodologicamente, propõe-se identificar, no âmbito do contexto histórico, o somatório de elementos epistemológicos positivos, que, desde os fundamentos clássicos da Ciência e do Estado moderno, aparecem e se reconstroem nas diversas fases históricas, até chegar a se constituir elemento institucional da escola na contemporaneidade.

Outro elemento metodológico importante a ser considerado inicialmente, no sentido da construção da análise deste texto, diz respeito à concepção teórica de política pública adotada neste texto. Isso porque se entende que, a partir do advento do Estado e da Ciência Moderna, se instituiu um parâmetro de verdade, de ciência, de comportamento individual, etc., e que esses atributos chegam à escola por meio das políticas educacionais.

Neste texto, utiliza-se o pressuposto de que o estudo das políticas públicas implica associá-las à teoria de Estado e, particularmente, às dimensões de classe, desconsiderando-se, portanto, os caminhos metodológicos normalmente utilizados nesse tipo de análise, associando-se políticas públicas a ações de governo, centralizando a atenção em avaliações de resultados e do gerenciamento dos recursos públicos. Considera-se, aqui, que associar políticas públicas à ação de governo traduz uma análise positiva da realidade desconhecendo-se as contradições, os conflitos e o contexto social, econômico e cultural onde tem origem uma política pública. Consequentemente, considera-se a necessidade de, ao se falar em políticas públicas, relacioná-las à teoria de Estado.

Quanto ao Estado, considera-se simplista, irreal e ideológico entender essa instituição simplesmente regida pela lei a serviço de todos os segmentos sociais. Portanto, não se utiliza, neste artigo, o pressuposto positivo segundo o qual a formulação das políticas públicas dá-se unicamente a partir de uma determinação jurídica, fundamentada em lei, como se o Estado fosse uma instituição neutra. Nesse caso, as políticas públicas seriam definidas tendo como parâmetro unicamente o bem comum, e esse bem comum seria entendido como de interesse de todos os segmentos sociais (BONETI, 2011).

Por outro lado, não se adota também o pressuposto de que o Estado constitui-se de uma instituição a serviço unicamente da classe dominante, desconsiderando-se, assim, as lutas sociais na perspectiva de construírem-se políticas públicas para atender demandas, ou de conflitos de interesses políticos, ideológicos e culturais. Adota-se, dessa forma, o pressuposto de que uma política pública, como as educacionais, tem origem no âmbito de uma complexidade. Assim considerando-se, adota-se, neste texto, o entendimento, inspirado na leitura de Poulantzas (1990), de que não é possível construir-se uma análise 
da complexidade que envolve a elaboração e a operacionalização de políticas públicas sem se levar em consideração a existência da relação intrínseca entre o Estado e as classes sociais, em particular entre o Estado e as classes dominantes.

\section{A construção da Razão Moderna: fundamento do pensamento positivo clássico presente nas políticas educacionais na contemporaneidade}

Considera-se que o atual "modelo civilizatório", entendido como uma sociedade tipicamente "racional", o qual se apresenta como referência para a institucionalização da educação brasileira, tenha sido construído a partir de dois movimentos históricos os quais se apresentam sincronizados e sintonizados com o fortalecimento da dinâmica capitalista de produção: a dinâmica histórica da construção das bases do conceito de cientificidade, a Ciência Moderna, e da organização social (Estado Moderno), o que se entendeu como a reconstrução da Razão; e o movimento burguês de consolidação da classe dominante com base no estilo de vida. Ambos serão analisados a seguir.

- Os caminhos históricos da construção das bases do conceito de cientificidade, de verdade e positividade

Os séculos XV, XVI e XVII testemunharam um expressivo movimento de construção do que se considera Ciência Moderna, no qual a expressão "razão" apresentava-se como carro chefe, a partir de dois enfoques: o método científico e a organização social (o Estado). "Razão" designava a busca de uma sociedade nova - comparativamente à sociedade feudal -, de uma sociedade racional com base na cientificidade e da superação do teologismo como método de explicação do real. Assim, Francis Bacon (1561) e Descartes (1596) buscavam a superação do teologismo, típico da sociedade feudal, enfocando atenção especial no Método da busca da verdade científica. Nesse momento histórico, três elementos aparecem importantes fazendo-se presentes como fundamentos epistemológicos das políticas educacionais na contemporaneidade: 1. A existência está associada à ideia do real, do concreto, do material; 2. A premissa do Método extrapola o mundo da ciência e designa comportamento "racional" do indivíduo, ou melhor, o agir com discernimento. Assim, já se tem um elemento importante para a análise que se faz neste texto, o que será retomado mais adiante: o nascimento da premissa do "ser normal" associada ao "ser racional"; 3. Institui-se um parâmetro de universalidade da cientificidade, daquilo que se diz verdade. Esse elemento é importante ser lembrado, pois é dele que tem origem a ideia etnocêntrica de verdade e do "correto" comportamento social, do que se entende como "certo" e como "errado", muito presente no conjunto de regras educacionais. 
A filosofia do jusnaturalismo, com Hobbes (1588) e Locke (1632), retomada por Rousseau (1712), com a premissa da "condição em natureza", justificando, assim, a necessidade de um "contrato social" entre os indivíduos, abre para se pensar em outro elemento de análise dentro dessa temática: a do indivíduo como foco central. Isto é, no mundo escolar não se lida com o social, mas com o indivíduo. Embora com diferentes perspectivas em relação à "condição em natureza" (fragilidade social do indivíduo em condições de natureza para Hobbes; o direito à propriedade na condição em natureza para Locke; e os males da propriedade privada para a condição em natureza para Rousseau) discutiase, na verdade, um projeto de sociedade racional, tendo como foco central o indivíduo. Em outras palavras, o movimento que busca a construção de uma sociedade com base na "razão" científica, inicialmente pela construção de um método científico, estipula, na realidade, parâmetros universais de ciência e de verdade, nos quais se encontra a origem da concepção etnocêntrica de sociedade, tendo como base o indivíduo.

O etnocentrismo, tendo como foco central o indivíduo, adota o entendimento segundo o qual existem sociedades que centralizam a verdade em termos de costumes culturais, desenvolvimento social e econômico etc. Essas sociedades têm dificuldade de compreender como verdade as diferenças culturais se não as suas. Segundo a concepção etnocêntrica, portanto, existe uma verdade única e universal, entendida como o centro, e é a partir dela que se instituem as atribuições do certo e do errado. $\mathrm{O}$ etnocentrismo tem origem justamente da razão científica, do entendimento de que a ciência é única e universal, que a verdade científica guarda requisitos universais que a distingue como ciência (GARCIA, 1999). É desse pensamento que nascem as atribuições do centro e da periferia, como atribuição de valor de verdade - que o centro retém mais e melhor tecnologia, mais riqueza, e mais verdade. Com isso nasce a tendência de atribuir-se modelos sociais, culturais e de desenvolvimento social. A partir dessa concepção, as necessidades dos grupos dominantes são absorvidas pelos setores pobres como suas, assim como a superação das carências da população pobre é feita utilizando-se, como referência, o jeito de ser dos grupos sociais dominantes.

A presença da concepção etnocêntrica no arcabouço institucional da escola é determinante, em especial a adoção do princípio da homogeneidade e do indivíduo, como fim da ação educacional, ou como meio de sua operacionalização. Em outras palavras, a ação da prática escolar parte do pressuposto de que há uma homogeneidade entre os indivíduos ao mesmo tempo em que o próprio objetivo desta ação é o de levar a homogeneização, não tratando os grupos sociais considerados "diferentes" como tais, mas na perspectiva de homogeneizá-los. Assim, a homogeneização apresenta-se na prática escolar como meio e como fim, tomando-se como parâmetro o "modelo civilizatório" burguês. 
Nessa trajetória da construção do preceito da "cientificidade", utilizado como parâmetro para o "modelo de civilidade", um aspecto faz-se importante ser analisado: o aproveitamento de ingredientes das ciências da natureza pelas ciências do homem. Isto é, o "modelo civilizatório" a partir do qual se estipula o parâmetro de "ser normal" contém ingredientes advindos das ciências da natureza. Com o avanço da ciência do domínio da natureza, a partir do método experimental, a física parece ser o primeiro ingrediente a integrar-se no processo da formação das ciências humanas. A economia política foi constituída na Inglaterra no decorrer da Revolução Industrial e da glória de Newton, quando se tinha uma influência considerável da epistemologia positivista. A partir de então, grandes teóricos das ciências do desenvolvimento econômico, como Adam Smith, Walras, Pareto e Saint-Simon desejavam ser o Newton da mecânica social da produção e do consumo de riquezas (GRINEVALD, 1975).

A construção das ideias das ciências humanas a partir das ciências da natureza fez com que esta, as ciências humanas, fosse assumindo ingredientes típicos das ciências naturais. O primeiro ingrediente que vem da física e que aparece claramente como parâmetro de "normalidade" nos dias de hoje diz respeito à ideia que associa o progresso da humanidade à força e à energia. Em síntese, o pensamento de Newton cruzou as fronteiras do mundo natural para o social. Assim, os teóricos precursores da chamada "ciência do desenvolvimento humano", como foi o caso de Saint Simon, Augusto Comte, etc., passaram a associar o "progresso humano" à ideia do movimento, da força e da energia.

Essa interpretação dava origem não apenas à ideia segundo a qual o desenvolvimento social está condicionado ao desenvolvimento industrial (o sinônimo do capitalismo), mas a que não existe singularidade no que se refere ao desenvolvimento social - ele é único e universal e que este está associado à ideia de movimento progressivo. Esse preceito tem importância na análise que aqui se faz em dois aspectos: o primeiro refere-se à associação da "normalidade", ao movimento evolutivo individual. Em outras palavras, o "normal" é o que "progride", "evolui", movimenta positivamente a vida, muito presente no processo da progressão escolar; o segundo aspecto, como se dá na indústria, a força que impulsiona o desenvolvimento não nasce do mesmo corpo (comunidade ou indivíduo, por exemplo), mas de uma força externa. É o mesmo que dizer que existe um centro no qual as ideias dito científicas encontram-se e dele nascem e impõem um padrão homogêneo a partir do qual devem se adaptar as singularidades. Ou melhor, comunidades ou pessoas que utilizam modelos singulares de produção da vida material e/ou social jamais podem se desenvolver socialmente a partir das suas próprias experiências, mas dependem do impulso da força de ideias e de tecnologias de comunidades externas. Isso faz com que se tenha a concepção de que existe alguém, de certo comportamento, condição social, cultural, etc., com 
mais verdade que a outra, e que esta outra carece de ajuda e que, por si só, não sai da "estagnação". Isto é, todo corpo imóvel precisa de um corpo em movimento para ser impulsionado. No mundo escolar, certamente esse preceito aparece no pressuposto de que a verdade encontra-se unicamente sob o domínio do mestre.

No âmbito desse processo de construção das ciências, do domínio da natureza, especialmente no século XVIII, a ideia do movimento, sem ser na perspectiva de se ver o real como essencialmente contraditório segundo a dialética, mas na perspectiva da evolução, originado especialmente da física e da biologia, faz com que se estipule como "normalidade" o comportamento individual e social associado ao movimento linear, progressivo. O próprio Condorcet, no século XVIII, no seu Esboço Histórico de Evolução do Espírito Humano (1794), uma das principais obras teóricas de referência utilizada por Augusto Comte, associava o mundo social ao natural a partir de dois aspectos importantes: a sugestão da utilização de métodos matemáticos no estudo dos problemas sociais e os princípios da evolução humana como leis naturais. Esse é um aspecto importante na análise que aqui se faz em decorrência do pressuposto da evolução do indivíduo como sinônimo de "naturalidade" e "normalidade". A escola parte deste pressuposto: o indivíduo "normal" é o que apresenta capacidade de evolução.

Assim, pode-se dizer que o grande avanço dos estudos no domínio da natureza teve uma influência muito grande no estabelecimento de parâmetros de "normalidade" do comportamento social e individual. É importante, por exemplo, lembrar a utilização da concepção darwinista na elaboração de parâmetros da "evolução humana", na medida em que criou o preceito que, como na natureza os organismos vivos tendem a se adaptar às dificuldades e a criar estratégias para competir, na sociedade existe uma competição natural entre os indivíduos, se constituindo em seleção natural, permanecendo os mais aptos. Trata-se de um pressuposto que, no mundo social, é utilizado como "natural" - os "mais capazes" constituírem-se "modelos" para os "menos capazes". Isso leva ao preceito da meritocracia como instrumento de seleção dos "mais capazes" no processo da ascensão social e o respeito às normas da hierarquia social. A meritocracia é um preceito base utilizado na prática educacional.

\section{O movimento positivo burguês de distinção de classe tendo como base o estilo de vida}

Como se fez referência acima, no processo histórico da consolidação do pensamento científico dominante de hoje, foram sendo liberados ingredientes para a formação do conceito de cientificidade, originados especialmente nas ciências da natureza, e apropriados pela classe burguesa como mecanismos de distinção de classe. Tais ingredientes, como é o caso da noção de cientificidade, 
evolução e homogeneidade, traduzem a ideia de "normalidade" e "civilidade" constantes no arcabouço institucional da educação. Assim, argumenta-se que, mesmo a institucionalização da educação, tendo como parâmetro o "modelo civilizatório" burguês, mantendo-se inalterado, novos processos sociais, a dinâmica econômica, social e cultural delineiam novos contornos para os fins e as significações da educação.

O estilo de vida tipicamente burguês constitui-se em parâmetro de "normalidade" de comportamento individual e social, especialmente a partir de um movimento que começa após a revolução industrial, unindo dois aspectos importantes: ingredientes originados na evolução histórica do conhecimento científico, especialmente os advindos das ciências do domínio da natureza, como foi analisado acima, e a apropriação da noção de cultura como mecanismo de distinção da classe burguesa.

Dispõe-se de muitos escritos sobre o movimento burguês de distinção de classe, mas Eric Hobsbawm (2005), no livro A Era do Capital, dedica uma atenção especial a essa temática no capítulo 13 denominado O Mundo Burguês. Diz o autor: "Os fenômenos mais superficiais são às vezes mais profundos. Comecemos nossa análise desta sociedade, que atingiu seu apogeu no período que tratamos, pela aparência das roupas que seus membros usavam [...]" (HOBSBAWM, 2005, p. 321). Ainda, o autor escreve: "Essa dualidade entre solidez e beleza expressa uma grande divisão entre o material e o ideal, o corpóreo e o espiritual, muito típico do mundo burguês, já que o espírito e ideia dependiam da matéria [...]" (HOBSBAWM, 2005, p. 323).

Norbert Elias (1994), no livro O Processo Civilizador, volume 1, especialmente no Capítulo 2, A Civilização como Transformação do Comportamento Humano, ou mais especificamente no item intitulado $O$ desenvolvimento do conceito de civilité, traz excelente contribuição para a compreensão do significado do movimento burguês de distinção de classe na construção dos fundamentos epistemológicos clássicos das políticas educacionais.

No âmbito desse movimento, a ideia de cultura aparece como elemento preponderante. No século XVIII, a noção de cultura esteve muito atrelada à ideia de razão, à construção de uma sociedade racional, à distinção do homem do universo natural, ao discernimento, ao somatório de saberes e de conhecimentos. No século XIX, graças à influência francesa e ao movimento positivista, essa noção amplia-se e é apropriada pela classe burguesa como qualificativo de distinção de classe, passando a significar tudo o que contribui ao enriquecimento intelectual e espiritual: habilidades, hábitos e saberes refinados e eruditos. Retoma-se a ideia da razão como discernimento do ser social na diferenciação entre o agir natural e o agir racional, estipulando-se regras e regulamentações no convívio 
social, das mais simples às mais complexas, em geral com foco na racionalização do comportamento do indivíduo, a exemplo do uso racional da sexualidade.

Com Comte, no século XIX, a cultura assume uma conotação associada à cientificidade na medida em que a sua noção absorve ingredientes originados do mundo científico, como já se analisou acima, quando dois aspectos tomam evidência e se impõem como elementos chaves como parâmetros de "civilidade": minimização da diversidade e valorização do princípio da temporalidade e da evolução. Seria então de se considerar que, a partir de uma concepção etnocêntrica, existe um "modelo" de comportamento social e cultural que deve ser seguido pelas organizações sociais ou pelos indivíduos que ainda não adotaram tais procedimentos de vida, mas que é uma questão de tempo.

Denys Cuche (2002), com o seu livro A Noção de Cultura nas Ciências Sociais, explicita com muita clareza o papel da cultura como elemento de distinção do estilo de vida burguês no século XIX, especialmente no capítulo 2, A Invenção do Conceito Científico de Cultura, em que o autor diz (CUCHE, 2002, p. 34): "[...] conceito de 'cultura'. A palavra está em voga, mas é utilizada, na maior parte dos casos, tanto na França quanto na Alemanha, com um sentido normativo". Isto é, normativo do estilo de vida tipicamente burguês. Nos meios burgueses instituiuse um estilo de viver fundamentado na ideia da cientificidade, do racionalismo clássico e da cultura, acentuado no esmero do comportamento, do vestuário, da ornamentação do lar, etc., com isso passando a ideia de sucesso, de evolução e de progresso. Assim se construiu o preceito burguês que associa o ser ao ter, que a evolução do espírito é condicionada à evolução da matéria.

A participação na vida pública passa a ser, na sociedade burguesa, algo importante não mais como elemento de distinção de classe, mas como entendimento de que caberia à classe burguesa a construção da "hegemonia" do "modelo civilizatório". É oportuno lembrar que para a construção dessa "hegemonia" do "modelo civilizatório", fez-se importante a formação acadêmica da elite, especialmente com alguns cursos distintos e essenciais na construção da hegemonia da classe burguesa, como foi o caso do Direito e da Medicina.

Esse movimento burguês de consolidação de um estilo de vida associado a um "modelo civilizatório" aparece muito claramente na arte dessa época. Um dos exemplos é o movimento impressionista do século XIX da pintura. Merece destaque a tela Olympia (de 1863), de Édouard Manet: a mulher burguesa deitada, em ambiente privado do lar, em trajes mínimos (o que ressalta um elemento importante do comportamento burguês, a privacidade), refletindo (com tempo para pensar), e a criada negra entregando-lhe um buquê de flores. A tela mostra bem a importância dada ao indivíduo como centro, expressando a concepção que o social (ou o público) começa com o individual e a própria divisão social 
do trabalho (entre o burguês e o não burguês) no âmbito desse privado. Esse mesmo modelo social é refletido nas telas de outros impressionistas da época, especialmente em Claude Monet com suas paisagens associadas aos costumes sociais da época e suas mulheres vestidas com esmero, assim como as telas de Vincent Van Gogh, entre outros.

Portanto, no geral, esse foi o "modelo civilizatório" de referência, utilizado como parâmetro de construção do arcabouço institucional da educação, no qual aflora o preceito do indivíduo, da evolução, da temporalidade, e da universidade da verdade e do estilo de vida burguês. Essa é a banda rígida e inalterável da prática escolar. Contudo, a dinâmica social e os diferentes processos sociais em diferentes momentos históricos contribuíram para oferecer às políticas educacionais diferentes significados quanto aos seus fins, como será analisado a seguir.

\section{Como se expressa nas políticas educacionais brasileiras o "modelo de civilidade" construído a partir da junção do advento da ciência moderna e do estilo de vida burguês}

Em diferentes momentos históricos ocorreram eventos envolvendo o mundo social, político, produtivo e cultural, repercutindo sobre as políticas educacionais daquele momento, alterando-as em termos dos fins e dos significados da educação embora o seu arcabouço institucional ficasse inalterado. Assim, analisa-se a seguir alguns desses acontecimentos e as diferentes feições das políticas educacionais em torno dos seus fins e significados.

- Educação associada à ideia da evolução social utilizando-se da cultura burguesa como parâmetro fim educacional

No período anterior à "Revolução burguesa" no Brasil, em torno da década de trinta do século passado, a educação apresentava-se como mecanismo repassador da cultura tomando como parâmetro o modelo burguês e racional europeu importado pelas oligarquias rurais. Nesse período, vê-se um modelo educacional no qual se adotava um conceito científico de cultura, mecanismos institucionais de acesso à cultura restritos à classe dominante e à minimização da diversidade. Com isso, na educação, adotava-se o preceito de homogeneização, temporalidade e evolução, tomando-se a cultura burguesa parâmetro fim das tarefas educacionais e seus significados.

A construção do modelo burguês como parâmetro de civilidade no Brasil toma uma trajetória diferente daquela analisada acima, a europeia, conforme analisa Florestan Fernandes (1976). Na Europa, o movimento burguês de "civilidade" originou-se a partir de dois movimentos sincronizados: o da epistemologia do conhecimento científico, do que ficou convencionado como 
verdade científica, especialmente com o movimento iluminista; e o da chamada Revolução Industrial, ou a própria denominada "revolução burguesa", tendo a urbanização como fenômeno central. No Brasil, em decorrência da "tardia" "revolução burguesa", a representação inicial de classe dominante fazia-se por meio das oligarquias rurais. Foram certamente estas que importaram o modelo formal de viver da burguesia europeia expressa na maneira de se vestir, na prática da erudição expressa pela música e pela arte, na divisão social do trabalho entre o homem e a mulher, etc. As oligarquias rurais assumiram a condição de "europeus no Brasil", isolando-se em relação ao restante da população (estabelecendo relações frequentes com a Europa mesmo em relação à educação dos filhos), fortalecendo uma visão negativa e discriminatória em relação ao povo brasileiro.

Oliveira Viana (1933), em seu livro Evolução do Povo Brasileiro, expressa muito bem o pensamento "oligárquico burguês" brasileiro do início do século $\mathrm{XX}$, avaliando o jeito de ser do brasileiro típico, a sua origem cultural, a relação com o trabalho, as moradias, a escolaridade, etc., tomando-se como parâmetro o etnocentrismo europeu. Assim, esse autor diferencia um estilo de vida que deve ser adotado, o originado da burguesia europeia e o que não deve ser adotado, o típico sertanejo brasileiro. Esse contexto fez com a cultura burguesa, tendo como referência o "eurocentrismo", se constituísse o fim e o significado educacional no Brasil nesse período histórico.

- O conhecimento positivo associado à técnica e à funcionalidade como instrumento de construção de um projeto de nação no Brasil

Com a "Revolução Burguesa" no Brasil, da passagem do modelo agro-exportador para o urbano-industrial, grandes acontecimentos trazem novas perspectivas para o Brasil e para os brasileiros e, com isso, novos significados conceituais à educação. Os fins educacionais expressos nas políticas educacionais são alterados mesmo sem mudar o arcabouço institucional descrito acima - da transmissão da cultura como requisito de evolução social para a preparação para a vida produtiva.

Nesse período, o movimento modernista expresso na arte, na cultura em geral, nos processos econômicos e na própria vida social, ao mesmo tempo em que consolida a classe burguesa urbana como a dominante, destitui-se o modelo cultural burguês como sinônimo de civilidade - aquele até então de domínio das oligarquias rurais. Isso se dá a partir de eventos diversos envolvendo a dinâmica social. O primeiro destes pode-se considerar o próprio advento da urbanização quando se afloram diferenciações de grupos sociais distintos nas periferias urbanas, destituindo-se a ideia do comportamento social homogêneo, interferindo até mesmo na noção clássica de cultura, adotando-se uma nova: o da expressão da vida, na perspectiva de Geertz (1989). 
Esse processo de mudança também está associado a outros eventos, pode-se citar como exemplo: a chegada ao Brasil de estudos científicos etnográficos, sociológicos e antropológicos para os quais o mundo cultural passou a ter outro enfoque; os estudos estruturais da cultura de Lévi-Strauss e a análise funcionalista da cultura de Malinowski como expressão da vida no presente, destituindo-se a relação histórica entre cultura e evolução social; a Semana da Arte Moderna de 1922, a qual contribuiu com a quebra do preceito associando cultura ao mundo formal burguês; as influências de alguns movimentos sociais urbanos americanos, como o "hip-hop", as artes, a música (blues e jazz) e a literatura, influenciando na expressão cultural das periferias urbanas; o Manifesto dos Pioneiros da Escola Nova (1932), expressão dos intelectuais almejando-se um modelo educacional nacional a serviço do projeto Brasil e a universalização do acesso à educação.

Tais movimentos trouxeram uma feição nova às políticas educacionais em relação aos seus significados conceituais e fins. Como bem salienta Dermeval Saviani (2011), finalmente o Estado apresenta-se como o articulador central das questões educacionais no Brasil. A presença do Estado como articulador central das questões educacionais já se evidencia com a própria criação do Ministério dos Negócios de Educação e Saúde, em 1930, assim como, em 1934, com a promulgação da Constituição estabelecendo a necessidade de um Plano Nacional de Educação, da gratuidade e da obrigatoriedade do ensino elementar. O novo enfoque da educação, como uma política pública voltada ao mundo produtivo, é apresentado, por exemplo, com a reforma do ensino secundário de Francisco Campos - então ministro da Educação e Saúde, em 1931, e, posteriormente, a sua ampliação durante a gestão de Gustavo Capanema. Mas, por outro lado, nesse período histórico, acentuou-se a associação da educação ao meio produtivo e, com isso, fortaleceu-se a utilização dos principais ingredientes dos fundamentos epistemológicos clássicos das políticas educacionais: a razão técnica funcional, a homogeneidade e a evolução.

\section{O fundamento epistemológico clássico da escola, a razão moderna e o advento de processos sociais novos: o resgate do sujeito, o discurso da cidadania e da inclusão social}

$\mathrm{Na}$ contemporaneidade, destitui-se o absolutismo da verdade técnica como parâmetro de definição de uma política pública, apresentando-se, ao lado do Estado e do meio produtivo, novos agentes definidores, trazendo ao debate novas lutas sociais como é o caso do resgate do sujeito e das identidades. No caso brasileiro, esse fenômeno vem ocorrendo com mais intensidade a partir da última década do século passado, graças a novos processos sociais originados do 
mundo globalizado. Com isso reforça-se o entendimento segundo o qual uma política pública resulta da dinâmica do jogo de forças que se estabelecem no âmbito das relações de poder, relações essas constituídas pelos grupos econômicos e políticos, classes sociais e demais organizações da sociedade civil. Tais relações determinam um conjunto de ações atribuídas à instituição estatal, que provocam o direcionamento (e/ou o redirecionamento) dos rumos de ações de intervenção administrativa do Estado na realidade social e/ou de investimentos (BONETI, 2011). Nesse caso, pode-se dizer que o Estado apresenta-se como um agente repassador à sociedade civil das decisões saídas do âmbito da correlação de força travada entre os diversos segmentos sociais, ganhando força, na contemporaneidade, agentes e ações insurgentes de reconstrução da identidade social, superando, assim, os fundamentos epistemológicos da Razão Técnica, na busca da reconstrução das identidades sociais, mesmo em um contexto ainda de nítidas contradições.

No entanto, o fundamento epistemológico clássico das políticas públicas educacionais com fundamento na Razão Moderna, na funcionalidade, na homogeneidade e na evolução, tendo a técnica como parâmetro de referência de verdade e de saber, continua constituindo o arcabouço institucional da escola, o que designa o perfil do fazer escolar. Delineia-se, dessa forma, um processo contraditório entre o advento de processos sociais novos, exigindo um novo proceder da escola, como o caso da receptividade das diferenças e das desigualdades sociais, e o engesso do conjunto de normas, de regras e de valores da escola tendo como base os fundamentos epistemológicos clássicos das políticas educacionais. Essa contradição expressa-se na forma como a escola lida com as diferenças e com as desigualdades e, também, com a própria inclusão social.

Assim, no mundo social, político e cultural, aparecem novos agentes definidores de políticas educacionais, construindo-se dispositivos jurídicos de acesso e convívio escolar igualitário, mas a institucionalização do fazer escolar continua inalterada. Essa contradição será analisada a seguir.

- O olhar positivo da escola sobre a igualdade e a desigualdade social

A noção de igualdade e de desigualdade social utilizada no dia a dia da escola constitui-se de uma construção social, não se restringindo ao contexto escolar. A construção da noção de condição social, elaborada a partir de parâmetros racionalistas e cientificistas de instâncias burocráticas do Estado, materializa-se no meio social, pela construção de identidades coletivas aos moldes, como Manuel Castells (1999, p. 22-25) pensa, de “[...] identidade legitimadora, introduzida pelas instituições dominantes da sociedade, no intuito de expandir e racionalizar sua dominação em relação aos atores sociais [...]”. Isso explica o fato de que alguns segmentos sociais, como as classes médias e altas, mais afinados com a 
racionalidade burguesa, utilizam os mesmos parâmetros de delimitação da condição social daqueles utilizados pelas instâncias burocráticas do Estado, conforme demonstra a pesquisa de Boneti (2004) realizada sobre a noção da condição social. Além dessa "identidade legitimadora" da qual se faz referência acima, pode-se considerar que a utilização de critérios racionalistas e etnocêntricos por alguns segmentos sociais na delimitação da condição social igual aqueles utilizados pelas instâncias burocráticas do Estado tem origem, também, na construção histórica de uma racionalidade capitalista, muito própria do mundo Ocidental, fundamentada na razão instrumental.

$\mathrm{Na}$ prática, no meio social e no espaço escolar, existe uma mistura de imaginário e de realidade na construção da noção de desigualdade, normalmente envolvendo diferentes conceitos que se entrelaçam, como é o caso da condição social e da diferença. Pensar sobre desigualdade implica pensar a condição social; pensar sobre a condição social implica pensar sobre diferença. A diferença aparece sempre como uma espécie de parâmetro de determinação da condição. A diferença explicita aquela condição social, aquele comportamento, aquele modo de produção da vida, que foge ao padrão convencional etnocêntrico. Portanto, a noção de diferença é vista de uma forma positiva enquanto que a noção da desigualdade aparece sempre com conotação negativa. Entretanto, a positividade da diferença acaba se restringindo ao discurso de forma que, na realização prática das relações sociais, a diferença acaba sendo submergida pela negatividade da desigualdade (BONETI, 2001).

A negatividade imbuída na noção de desigualdade nasce dos parâmetros utilizados para determinar uma condição social julgada "digna" para o sujeito social. Nesse caso, a desigualdade estaria associada a uma condição social dita inferior, o desigual seria o pobre e não o rico, o diferente seria o pobre e não o rico, mesmo que o pobre se apresente na maioria. A diferença entre um e outro sujeito social acaba sendo associada tanto pelo imaginário social quanto pelas instâncias burocráticas do Estado, como é o caso da escola, com o ser do sujeito em lugar do estar. Isto é, deixa de ser uma condição passageira do sujeito social para se constituir numa condição perene, ou até em uma qualidade ou em uma racionalidade (BONETI, 2001, p. 120).

O mundo social, assim como a própria escola, utiliza como critério de delimitação da condição social não apenas determinantes quantitativos, como é o caso da renda, mas especialmente critérios associados ao perfil individual e à racionalidade técnica burguesa. Essa construção social da noção de desigualdade faz dos iguais os desiguais. Por exemplo, pessoas humildes que se vestem iguais, que igualmente todos têm aperto no orçamento, com uma condição social similar, tornam-se diferentes se comparadas a uma pessoa que tem hábitos luxuosos de consumo, que se veste diferentemente de todos. Esta última torna-se sozinha a 
igual, porque o padrão dela é o utilizado pelo conjunto social como referencial para se estabelecer parâmetros de definição da condição social, pelo fato de ser acolhido pela racionalidade burguesa. Os demais, mesmo em maioria, tornamse, perante ela, os desiguais. Por quê? Porque a igualdade não se estabelece pela maioria, mas a partir do conceito do padrão, que, na nossa sociedade capitalista, é imposta pelas classes dominantes. O igual assume uma posição de comando, para não dizer de dominador ou no mínimo de superioridade, perante o diferente.

Em outras palavras, a noção de desigualdade que se manifesta no mundo escolar, além de ter origem nas relações da vida real, estabelece parâmetros de delimitação da condição social envolvendo relações de dominação, que faz florescer ainda mais a desigualdade. Portanto, existe uma relação de dominação até mesmo na utilização dos parâmetros para delimitar as condições sociais. Esses parâmetros partem de critérios valorativos envolvendo habilidades, bens reais, culturais e simbólicos normalmente em poder de segmentos sociais dominantes. Trata-se, portanto, de uma noção de desigualdade assentada sobre a capacidade individual do acesso ao capital social e cultural. Esse é o fundamento da adoção do estigma de "grupos minoritários" ou dos "diferentes" os quais, em geral, são maioria. Essa mesma lógica é utilizada na definição do conceito de ciência e do saber utilizada e produzida pela escola.

- O olhar positivo da escola sobre a Inclusão Social

Uma interpretação teórica e/ou um conceito de uma ação social pode não representar verdadeiramente a realidade definida, trazendo, muitas vezes, prejuízos sociais. É o caso da exclusão e especialmente o da inclusão social. Como será analisada a seguir, a expressão "incluir" minimiza a ideia da promoção do acesso (aos bens e aos saberes socialmente construídos) e fortalece a ideia da concessão, jogando as pessoas para o campo da passividade, retirando delas o caráter de sujeito. Para compreender essa armadilha contida no conceito de inclusão social é preciso começar analisando a palavra-mãe: a exclusão social.

Falar em termos de classes e de desigualdades, segundo Robert Castel (2006), é referir-se à concepção clássica da sociologia, que prevaleceu até meados da década de 1970. De acordo com essa concepção, o coração da questão social é o conflito que opõe grupos sociais homogêneos em luta pela repartição dos benefícios do crescimento. A noção da exclusão social aparece mais tardiamente, com a crise da representação da questão social a partir da classe e da desigualdade social. Mas o aparecimento da noção da exclusão social não significou, necessariamente, a substituição da classe social e da desigualdade como representação da questão social. 
A noção da exclusão social aparece quando, no contexto social, tornou-se impossível a formalização do vínculo com a produção pela maioria da população, como outrora, quando se permitia a existência de grupos sociais homogêneos, como é o caso das classes sociais. Assim, a noção da exclusão social aparece exatamente no momento em que o sistema econômico quebra essa homogeneidade, impondo um processo de individualização. Nesse caso os "excluídos", segundo Robert Castel (2006), não constituem, a bem da verdade, de um grupo homogêneo. São mais precisamente coleções de indivíduos separados de seus pertencimentos coletivos, entregues a si próprios, e que acumulam a maior parte das desvantagens sociais: pobreza, falta de trabalho, sociabilidade restrita, condições precárias de moradia, grande exposição a todos os riscos de existência etc. Portanto, ainda para o citado autor (2006), falar em exclusão social refere-se à inquietação geral diante da degradação das estruturas da sociedade salarial, sublinhando-se a necessidade de se ocupar das vítimas dessa transformação. Assim, para um bom entendimento, não se trata de considerar a exclusão social como uma categoria de análise, assim como é a da classe social, mas sim de uma problemática social.

Essa interpretação atribuída à exclusão social, exposta acima, é atual e cultuada pela academia francesa, em especial nas obras de Robert Castel (1997, 2006) e Serge Paugam (1996). Mas não foi sempre assim. O percurso da noção da exclusão social passou por uma trajetória histórica tortuosa motivada por vários fatores. Em primeiro lugar, em decorrência da origem positivista da noção da exclusão social, cujo método da busca da compreensão da realidade social, privilegia o olhar dual e estático das relações sociais. Assim, excluídas seriam as pessoas que estivessem fora do social, como os leprosos, os marginais, os doentes mentais etc. Trata-se de uma visão funcional de caracterizar um contingente populacional que estaria fora, à margem da sociedade, conforme se expressou René Lenoir, considerado o criador dessa noção, no livro $L$ Éxclus, publicado em 1974. Em segundo lugar, a própria origem positivista da noção de exclusão criou entraves na utilização dessa noção na academia, em especial na brasileira, pela incompatibilidade do pressuposto de sociedade que essa noção trazia de sua origem com os estudos realizados pela academia crítica, especialmente a marxista, utilizando-se o referencial de classe. Em terceiro lugar, a trajetória histórica dessa noção determinou o aparecimento de uma confusão metodológica a partir do entendimento de que a noção da exclusão social se constituísse de uma categoria de análise, assim como o de classe social. A partir de tal entendimento, seria incompatível falar ao mesmo tempo de classe e de exclusão social. Assim, é possível se falar ainda em exclusão social, sobretudo se considerar-se a caminhada já realizada desse conceito na academia adotando a significação dada pelos autores acima referidos. Nesse caso, não significa incompatibilidade associar exclusão social como problemática social, e classe social como categoria de análise. 
Contudo, com a noção de inclusão é diferente, especialmente quando se refere a programas sociais e educativos de promoção do acesso aos bens e aos saberes socialmente construídos, apresentando maiores complicadores. Além de guardar consigo o significado original da exclusão, não se pode dizer que essa palavra constitua-se de uma noção ou de um conceito. Trata-se de uma positivação em relação a uma problemática social, a da exclusão, segundo o entendimento original já considerado. Portanto, é mais um discurso do que um conceito. Além dessa pobre origem, agregou, durante a sua pequena história de vida, antigos ingredientes da política. O entendimento do social a partir de uma concepção dual do dentro e do fora já foi utilizado pelos contratualistas, em particular por Hobbes e Rousseau, fornecendo bases à sociologia política positiva e ao Direito.

No seio dessa concepção, umas das noções que nasceu e persiste até nos nossos dias é a noção de cidadania. A noção de cidadania que persiste nos dias atuais, e que conserva uma proximidade com a noção do ser incluído/a, é aquela associada aos direitos constitucionais. Em outras palavras, o entendimento do social a partir de uma concepção do dentro e do fora pode ter origem, antes de tudo, da noção de cidadania, ou de cidadão, a pessoa que estivesse "incluída" em uma sociedade racional, em uma sociedade de direito, em uma sociedade de Estado (sociedade contratual). Com o advento da sociedade industrial e a complexidade inerente à urbanização, avolumou-se a dependência da sociedade civil frente às políticas sociais do Estado, quando esta interpretação dual de sociedade, entre os "incluídos" no contrato social e os "excluídos" dele, ampliou-se ainda mais.

Nessa perspectiva, a pessoa "incluída" seria a pessoa juridicamente cidadã, isto é, com direitos e deveres frente ao contrato social, com direitos e deveres de votar e ser votado e usufruir dos direitos sociais básicos. Pode-se dizer que essa concepção de cidadania restringe o indivíduo a uma posição passiva na sociedade, isso porque se garante a participação do indivíduo por vias formais, na medida em que esse indivíduo é "incluído" formalmente, juridicamente, como cidadão que vota, que tem opinião, que produz. Mas esse entendimento de cidadania não atribui qualificativo de cidadania a uma pessoa que não vota, que não tem trabalho, que não opina.

Em síntese, o conceito de inclusão carrega consigo dois pesos desfavoráveis: $\mathrm{O}$ primeiro deles diz respeito à sua herança teórica e metodológica utilizada para a sua formulação, o da dicotomização do dentro e do fora, coisa que a sua palavra-mãe, a exclusão, já superou ou, no mínimo, está em processo conforme visto em páginas anteriores neste trabalho. O segundo diz respeito à agregação de ingredientes conservadores da sociologia política, associando a inclusão à cidadania, enquanto condição de estar incluída no "contrato" social e, assim, usufruir de direitos. Ambas as situações fazem com que a palavra inclusão 
assuma uma significação da existência de um único projeto político de sociedade, o da classe dominante, reservando-se a essa classe o monopólio do controle do acesso aos serviços públicos, aos bens sociais, aos saberes, aos conhecimentos tecnológicos, à cultura etc.

- O olhar positivo da escola sobre a cidadania

Nos dias atuais, a cidadania é invocada em diferentes situações. A palavra cidadania está presente nos espaços públicos, nas conversas informais, nos programas e nos projetos governamentais, etc. de forma que fica um pouco difícil encontrar um significado uniforme que una todas as situações em que essa palavra é utilizada. Certamente, hoje, a noção de cidadania extrapola o seu significado oriundo com o advento do Estado moderno, quando essa condição estava ligada a ter direitos e deveres dos indivíduos frente à organização social, o Estado, quando a utilização de cidadania estava associada a esses direitos e deveres. Atualmente, essa noção extrapola o ter direito e dever como indivíduo, aparecendo outros ingredientes como condição de cidadania, como é o caso da participação e do pleno acesso aos bens e aos saberes socialmente construídos. Isso significa dizer que, no mundo social e escolar, a noção cidadania ampliou-se na direção do acesso, avançando para o além do ter direitos.

No entanto, no âmbito do institucional, do Estado e mesmo da própria escola, e da organização produtiva, não é bem assim. O ideário neoliberal alia a premissa das liberdades individuais à diminuição das funções do Estado. A partir dessa premissa, desloca-se o indivíduo como elemento social sob a proteção do Estado, acentuando nas capacidades e nas responsabilidades individuais a construção do acesso aos bens e aos saberes socialmente construídos. Nesse caso, a implementação do direito e do acesso passa a ser do indivíduo.

Em países como os da América Latina, onde o Estado tende a se fragilizar justamente pela exagerada aproximação deste com a classe economicamente dominante, o exercício da cidadania já não mais se encontra sob a égide do Estado, mas das relações econômicas e sociais. O Ser cidadão não mais significa apenas ter direitos, mas possuir um conjunto de habilidades e/ou capital que o faz Ser, nunca de responsabilidade do Estado, mas do indivíduo. Nesse caso, a cidadania não é vista como uma noção, associando uma condição social atrelada a direitos e a deveres frente ao Estado, mas cidadania apresenta-se como um discurso associando-a à capacidade individual. Nesse contexto, as políticas públicas, especialmente as educacionais, colocam-se como instrumento de preparação das individualidades em relação às habilidades e às condições requeridas pelo mundo da produção, assim como os requisitos necessários para a participação dos indivíduos na produção e no consumo. 
É com essa noção de cidadania que a escola recebe em seu espaço as desigualdades e as diferenças sociais. De um lado acena para o discurso da inclusão social, mas, por outro lado, as regras escolares privilegiam os indivíduos que se apresentam "capazes" de mostrar evolução e se enquadram no processo da homogeneização do espaço da escola.

\section{Considerações finais}

Ao longo deste texto, evidenciaram-se elementos chaves que aparecem no processo histórico da construção da Ciência e do Estado Moderno e outros fatores entrelaçados, originados na racionalidade burguesa, os quais constituem, em conjunto, os fundamentos clássicos da epistemologia das políticas educacionais e do fazer da escola na contemporaneidade. A leitura metódica dessas passagens históricas leva a concluir que o acolhimento das diferenças no espaço escolar está diretamente condicionado a duas instâncias: à organização jurídica, política e institucional com regulações expressas nas políticas públicas educacionais e à prática do dia a dia da escola.

No que concerne à regulamentação, pode-se considerar que já se conta com uma política de acolhimento das diferenças na escola. Porém, mesmo considerando-se que a existência do instrumento jurídico na perspectiva de implementar-se uma ação já é um avanço, essa política ainda se restringe ao universo do direito, em uma perspectiva de concessão, sem que as diferenças e as desigualdades sociais sejam consideradas como "iguais" no espaço escolar. Isso ocorre porque a prática do dia a dia da escola continua baseada nos fundamentos epistemológicos clássicos das políticas educacionais, como se identificou ao longo deste texto, especialmente no que se refere ao fato de associar-se o conhecimento escolar à funcionalidade técnica e de considerar-se, também, a normalidade às capacidades individuais de evolução.

Assim considerando, entende-se que a absorção do conhecimento, quer seja por meio da escola ou do contexto social, assume um caráter ideológico no qual a ideia da progressão (tanto no interior da escola, a seriação, como na própria vida da pessoa) se faz fundamental. Isto é, a ideia da progressão na absorção do conhecimento constitui-se de um dos principais elementos da racionalidade burguesa. Essa noção constitui-se de um caráter ideológico porque exige que o sujeito social acredite que a escola lhe fará absorver, progressivamente, o conhecimento dominantemente requerido pelo contexto social. Esse é um fator que se pode considerar um entrave para a receptividade pela escola das diferenças e das desigualdades sociais, uma vez que esse elemento ideológico por si só divide o grupo social e/ou escolar entre os considerados "capazes" e "não capazes". Esse fenômeno ideológico do saber agrava-se na contemporaneidade no contexto da 
dinâmica da globalização da cultura e das relações econômicas, evidenciando traços ideológicos que atendem a uma racionalidade técnica e instrumental, muito própria e propícia do modelo capitalista vigente. A ciência desenvolve-se de forma conjugada à expansão das atividades econômicas, e, nesse caso, o progresso técnico assume um caráter ideológico de racionalidade. O caráter ideológico do progresso técnico é perfeitamente perceptível ao se associar o conceito de racionalidade à forma capitalista de atividade econômica.

Assim, mesmo que a dificuldade da receptividade das diferenças e das desigualdades sociais expressa-se mais nitidamente na prática do dia a dia da escola, fundamentada ainda na razão técnica e funcional, não é necessariamente na escola que a origem do problema encontra-se. A prática da escola insere-se no âmbito de um modelo taylorista de divisão do fazer e do pensar. A escola recebe de instâncias burocráticas do Estado atribuições do fazer escolar como simples procedimentos técnicos por meio dos quais o fazer e o pensar distanciam-se enormemente. O pessoal da escola não tem tempo para pensar, produzir e transmitir conhecimento, restringindo-se ao mero fazer.

\section{Referências}

ALMEIDA, M. de L. P. de; SILVA, S. R. da. A perspectiva epistemológica de Gramsci e a pesquisa de políticas educacionais. In: TELLO, C.; ALMEIDA, M. de L. P. de. (Orgs.). Estudos epistemológicos no campo da pesquisa em política educacional. Campinas: Mercado de Letras, 2013. p. 229-242.

ALMEIDA, M. de L. P.; TELLO, C. Consolidando o campo da investigação em Política Educacional. In: TELLO, C.; ALMEIDA, M. de L. P. (Orgs.). Estudos epistemológicos no campo da pesquisa em Política Educacional. Campinas: Mercado de Letras, 2013.

BLASCO, C. M. Etnografía en análisis de políticas educativas: reflexiones epistemológicas desde América Latina. In: TELLO, C. (Org.). Epistemologías de la política educativa: posicionamientos, perspectivas y enfoques. Campinas: Mercado de Letras, 2013. p. 421-446.

BONETI, L. W. Ser ou estar pobre? A construção social da noção da desigualdade. Revista Contexto \& Educação, Ijuí, v. 16, n. 62, p. 115-134, abr./jun. 2001.

BONETI, L. W. L'exclusion sociale en tant que trajectoire de perte d'accès à des biens et des services. Bulletin de 1'Association internationale des sociologues de langue française, Toulouse-Le, n. 20, p. 149-166, 2004.

BONETI, L. W. Políticas públicas por dentro. 3. ed. Ijuí: Editora Unijuí, 2011.

CASTEL, R. As armadilhas da exclusão. In: BELFIORE-WANDERLEY, M.; BÓGUS, L.; YAZBEC, M. C. (Org.). Desigualdade e a questão social. São Paulo: EDUC, 1997. p. 15-48.

CASTEL, R. Classes sociais, desigualdades sociais, exclusão social. In: BALSA, C.; BONETI, L.; SOULET, M. H. (Org.). Conceitos e dimensões da pobreza e da exclusão social. Ijuí: Editora Unijuí, 2006. p. 63-77. 
CASTEL, R. De l'indigence à l'exclusion, la désaffiliation. Précarité du travail et vulnérabilité relationnelle. In: DONZELOT, J. (Org.). Face à l'exclusion, le modèle français. Paris: Éditions Esprit, 1991. p. 137-168.

CASTELLS, M. A sociedade em rede. São Paulo: Paz e Terra, 1999.

COMTE, A. Curso de Filosofia Positiva; Discurso Preliminar sobre o conjunto do Positivismo; Catecismo Positivista. 5. ed. São Paulo: Nova Cultural, 1991.

CONDORCET, J. A. N. C. Esquisse d'tableau historique des progrès de l'esprit humain. 1794. Disponível em: < http:/ / www.classiques.uqac.ca/esquisse_tableau_progres>. Acesso em: 28 set. 2013.

CUCHE, D. A noção de cultura nas ciências sociais. 2. ed. Bauru: EDUSC, 2002.

ELIAS, N. O processo civilizador. Rio de Janeiro: Zahar, 1994.

FERNANDES, F. A revolução burguesa no Brasil. 2. ed. Rio de Janeiro: Zahar, 1976.

GARCIA, C. B. As cidades e suas cenas. Ijuí : Editora Unijuí, 1999.

GEERTZ, C. A interpretação das culturas. Rio de Janeiro: LTC, 1989.

GOROSTIAGA, J. M. Un abordaje de la cuestión epistemológica en los estudios comparados sobre política educativa. In: TELLO, C. (Org.). Epistemologías de la política educativa: posicionamientos, perspectivas y enfoques. Campinas: Mercado de Letras, 2013. p. 239- 268.

GOROSTIAGA, J. M.; TELLO, C. La cartografía social y el pluralismo como enfoque epistemológico para el análisis de políticas educativas. In: TELLO, C. (Org.). Epistemologías de la política educativa: posicionamientos, perspectivas y enfoques. Campinas: Mercado de Letras, 2013. p. 447-476.

GRINEVALD, J. Science et développement: esquisse d'une approche socio-épistémologique. In: La Pluralité des mondes - Cahier de l'I.E.D.1, Genève et Paris: P.U.F, 1975. p. 31-97.

HOBSBAWM, E. A era do capital. 11. ed. São Paulo: Paz e Terra, 2005.

KAPLAN, C. V.; NAPOLI, P. di. La categoría de capital cultural en Pierre Bourdieu para el análisis de políticas y las prácticas educativas. In: TELLO, C. (Org.). Epistemologías de la política educativa: posicionamientos, perspectivas y enfoques. Campinas: Mercado de Letras, 2013. p. 383- 420.

LENOIR, R. L’ exclus. Paris: Le Seuil, 1974.

MAINARDES, J.; GANDIN, L. A. A abordagem do ciclo de políticas como epistemetodologia: usos no Brasil e contribuições para a pesquisa sobre políticas educacionais. In: TELLO, C.; ALMEIDA, M. L. P. Estudos epistemológicos no campo da pesquisa em política educacional. Campinas: Mercado de Letras, 2013. p. 143-167.

MASSON, G.; MAINARDES, J. Las contribuciones de la perspectiva marxista para la investigación sobre políticas educativas. In: TELLO, C. (Org.). Epistemologías de la política educativa: posicionamientos, perspectivas y enfoques. Campinas: Mercado de Letras, 2013. p. 319-348.

PAUGAM, S. L'éxclusion - l'état des savoirs. Paris: L'édition la Découverte, 1996.

POULANTZAS, N. O estado, o poder, o socialismo. 3. ed. Rio de Janeiro: Graal, 1990. 
RUIZ, G. El enfoque jurídico normativo de la política educacional. In: TELLO, C. (Org.). Epistemologías de la política educativa: posicionamientos, perspectivas y enfoques. Campinas: Mercado de Letras, 2013. p. 109-162.

SAVIANI, D. A política educacional no Brasil. In: STEPHANOU, M.; BASTOS, M. H. C. (Org.). Histórias e memórias da educação no Brasil. vol. I: séculos XVI-XVIII. Petrópolis: Vozes, 2011. p. 131-140.

SAVIANI, D. Epistemología de las políticas educativas: algunas precisiones conceptuales. In: TELLO, C. (Org.). Epistemologías de la política educativa: posicionamientos, perspectivas y enfoques. Campinas: Mercado de Letras, 2013. p. 495-500.

TELLO, C. Las epistemologías de la política educativa - Notas históricas y epistemológicas sobre el campo. In: TELLO, C. (Org.). Epistemologías de la política educativa: posicionamientos, perspectivas y enfoques. Campinas: Mercado de Letras, 2013. p. 23-68.

VIANA, O. Evolução do povo brasileiro. São Paulo: Nacional, 1933.

Recebido em 28/01/2013

Versão final recebida em 13/04/2014

Aceito em 15/04/2014 